\title{
Free Voluntary Reading: Promoting Vocabulary Learning and Self-Directedness
}

\author{
Diana Carolina Durán Bautista ${ }^{1} \&$ Mario Alberto Rendón Marulanda ${ }^{1}$ \\ ${ }^{1}$ Department of Foreign Languages and Cultures, Universidad de La Sabana, Colombia \\ Correspondence: Diana Carolina Durán Bautista, Department of Foreign Languages and Cultures, Universidad \\ de La Sabana, Chía, Colombia. Tel: 57-1-8615555, ext. 41339. E-mail: diana.duran2@unisabana.edu.co
}

Received: May 23, 2018 Accepted: July 10, 2018 Online Published: July 12, 2018

doi: 10.5539/elt.v11n8p51 URL: http://doi.org/10.5539/elt.v11n8p51

\begin{abstract}
This action research study focuses on measuring the impact of a Free Voluntary Reading Program on students' active vocabulary use and self-direction in language learning in two different programs of English as a foreign language. The impetus for this research came from close observation and a needs analysis that confirmed students' reluctant attitude towards reading, due to deficiency in vocabulary, as well as the limited access to books of their interest in the target language. The implementation of the program took place in blended classes in two university contexts, with 14 and 11 students respectively. All the students from both universities were classified in the A1 level according to the Common European Framework of Reference for Languages and their ages ranged from 16-21 years. The data was collected using a pretest and a posttest, students' diaries, pre and post implementation surveys and book reviews. The program attempted to promote extensive reading, self-direction, reading habits, vocabulary gain and a more positive attitude towards written stories.

Keywords: extensive reading, free voluntary reading, vocabulary acquisition, reading habits, autonomy, vocabulary strategies.

\section{Introduction}

English is perceived as important to economic, cultural and educational fields in Colombia. Thus, the educational community is well aware of the commitment to provide undergraduate students with foreign languages skills that will help them succeed in their future professional lives. This importance poses a significant challenge to university learners, who need to be proficient in English in order to obtain an adequate academic performance and to meet the requirements for graduation. Besides, it is quite common nowadays to find a large number of higher education institutions that require students to take subjects and consult literature in English. A particularly helpful option is the implementation of extensive reading programs, which motivate students to read texts for general understanding and enjoyment, making free voluntary reading an attractive approach to language learning, since it provides students with pleasurable and motivating opportunities to see words used in context (Thornbury, 2002) and at the same time, to develop autonomy.

Considering how essential it is to find a way of boosting reading habits in undergraduate students, the present study aims at examining the effects of a research project focused on Free Voluntary Reading (FVR hereafter), on English as a foreign language (EFL) learners' active vocabulary acquisition as well as self-direction levels.
\end{abstract}

\subsection{Setting and Population}

The implementation of this free voluntary reading study, as a way to promote extensive reading, took place in two different contexts: a private university outside Bogotá, Colombia (context 1) and a private university located in Ibagué, Colombia (context 2). The two groups of participants were composed of undergraduate students from different academic programs who shared the same English proficiency level: A1 in agreement with the Common European Framework of Reference (CEFR). Both universities require students to reach a B2 level to graduate, this means that all the participants needed to advance from basic to independent levels before graduation. The students' ranged from 16 to 21 years old.

\subsection{Problem Statement}

The impetus for this research came from close observation and a needs analysis that confirmed students' reluctant attitude towards reading, due to deficiency in vocabulary as well as the limited access to books of their interest in the target language. As a starting point, the researches applied a diagnostic survey to find out students' 
initial habits, attitudes and perceptions towards reading (Appendix A). Findings showed that although students claimed to be motivated to read in English, they did not do it on a regular basis. Students also reported some difficulties they had when reading on their own: lack of vocabulary to understand the text, lack of interest on the available books in English and a perceived difficulty to read those books. The data collected in this entry survey will be contrasted with the results of an exit survey after the implementation of the study in a further section of this paper.

Based on the problematic stated above, throughout the implementation of a Free Voluntary Reading Program in combination with vocabulary learning strategies instruction (Guessing Meaning from Context and Dictionary Use) in a blended environment, the study aims to answer the following question:

How does the implementation of a Free Voluntary Reading Program in combination with vocabulary learning strategies, affect active vocabulary acquisition and self-direction in language learning in A1 EFL learners?

Correspondingly, the study intends to:

- measure to what extent the implementation improves students' immediate use of active vocabulary and word retention.

- $\quad$ examine the correlation between self-directedness (Independence from teacher/translator and strategies use) and vocabulary acquisition.

- $\quad$ assess students' improvement in free voluntary reading habits such as frequency of reading and reading interest after the implementation.

Before discussing how these questions and objectives were addressed, it is essential to review first the theoretical constructs that guided this study.

\section{Theoretical Framework}

\subsection{Free Voluntary Reading}

Krashen (2004), probably the most avid advocate of Free Voluntary Reading (FVR), defines it as "reading because you want to, no book report, no questions at the end of the chapter. FVR means putting down a book you don't like and choosing another one instead" (p. 10). FVR, also known as reading for pleasure, has been demonstrated to have a profound impact on the development of a language learner's cognitive processes concerning other language skills. For instance, those students who read more also demonstrate better writing skills (Krashen, 2004). Furthermore, learners who read extensively also improve their grammatical competence (Lee, Krashen, \& Gribbons, 1996). Krashen (2004) also mentioned that FVR is the source of competences in reading, vocabulary, spelling and writing style, among other benefits.

\subsection{The Effectiveness of Reading for Vocabulary Learning}

The enormous influence of reading on vocabulary knowledge has been reported abundantly. For instance, Hu and Nation (2000) affirm that vocabulary and reading comprehension have two major effects; one is the effect of vocabulary knowledge on reading comprehension and the other is the effect of reading comprehension on vocabulary growth. Although both effects are equally significant and closely related, this paper focuses especially on the second one, where vocabulary growth takes place while reading for pleasure.

Moreover, particularly interesting to the purposes of this study, literature shows that reading enhances vocabulary and spelling skills (Lee, Krashen, \& Tse, 1997; Cho, Park, \& Krashen, 2008). Similarly, Liu and Zhang (2018) analyzed the effectiveness of extensive reading on vocabulary learning in EFL environments, Results proved the significantly positive effect that extensive reading can have on English vocabulary learning. $\mathrm{Hu}$ and Nation (2000) also affirm that when the learner controls the reading skills, reading becomes a mean of vocabulary growth. Hence, for controlling the reading skills, the reader needs to solve the issues blocking comprehension in order to start their vocabulary acquisition process through reading new words. For students to solve the issues that arise, training learners on vocabulary meta-cognitive strategies may play a central role.

\subsection{Use of Active Vocabulary}

Once the student knows a word, He/she can better understand it by reading it in context or using it in oral or written production, this is evidence of more active vocabulary use (The British Council, 2008). In this study, researchers measured the number of words students used when writing reviews, after seeing them in context when reading.

Laufer and Hulstijn (As cited in Laufer, 2001) propose a motivational-cognitive construct of involvement, in which they include the component of "the need". The authors state:

Need is moderate when it is imposed by an external agent, and strong when it is intrinsically motivated - that is, self-imposed by the learners. For example, a moderate need occurs when 
the teacher asks the student to fill a word in a sentence, while a strong need occurs when the learner decides to look up a word in an L1-L2 dictionary during composition writing. (p. 50)

Based on this definition, the researchers attempted to create "a strong need"; by writing reviews, students needed to use actively the vocabulary encountered in graded readers.

\subsection{Graded Readers}

For reading comprehension and vocabulary learning to take place, learners must know 98 percent of the running words in advance (Hu \& Nation, 2000). Hence, graded readers are major means of learning from input, since they contain controlled vocabulary according to student's' English proficiency levels; that is why Liu and Zhang (2018) suggested that teachers should adopt graded readers as extensive reading books. Research has also shown that those students with access to books interest to them tend to read more and better (Krashen, 2004; McQuillan, 1998). Therefore, a more powerful way to motivate students to read more is by offering them a wide range of books within their proficiency level: graded readers. Besides, if the comprehension of the text is interrupted, few new words can be learned through guessing from context (Nation, 2001). That is, texts must be adapted to the learners' level, and students must be provided with profitable strategies to overcome any vocabulary issue that could block understanding.

\subsection{Guessing Approach and Dictionary Use}

As mentioned above, guessing based on context is one of the main strategies for boosting vocabulary learning through reading comprehension. Vocabulary can be learnt incidentally by meeting new words in context. Edwards (2009) says that when a new word is seen in context, students can notice how the new item works grammatically and, in this way, the word will be easier to remember. Thornbury (2002) agrees that words in context provide learners with the opportunity to appreciate not only their meaning but also their usual environments, such as their collocations or grammatical structures. Krashen and Terrell (2000) argue that 'memorized' or 'drilled' vocabulary is not stored in long-term memory; this is why it is important to give a context when learning new words. The authors above assert that this strategy permits students to learn vocabulary without the teacher's assistance; in this way, students are self-empowered and become more autonomous.

Still, it is important to mention that the vocabulary guessing approach is not adequate in all the cases. Laufer and Yano (2001) argue that guessing is not always a trustworthy strategy as the contextual cues may be confusing and may not be sufficient at times, so it is necessary to reinforce the reading sessions with a second strategy like dictionary use. However, students might have serious difficulties when reading if they do not manage the skill of using a dictionary correctly (Clarke \& Nation, 1980; Boonmoh, 2012). The authors recommend that in the case of encountering non-guessable words, which are necessary for the comprehension of the text, learners should look up the unknown vocabulary in a dictionary. To do so, the authors suggest to look up the word in a dictionary and to choose, between the varieties of meanings given, the one that fits the context better.

Consequently, the guessing from context approach and dictionary use complement each other, since the dictionary is recommended as a second step in cases where the context does not offer enough information to guess the word. These strategies also provide students with skills to carry on reading sessions without the assistance of the teacher or the translator; by reading freely, students are expected to show vocabulary growth and to become more self-directed.

\subsection{Self-Direction in Language Learning}

Giving students the opportunity to make their own decisions is essential for the success of self-guided reading programs. Griffiths (2008) asserts that self-directed learning fosters successful language learning by allowing students to become more autonomous. The importance of self-direction is well noted by Hiemstra (1994) who remarks, "Learners will need to become very self-directed throughout their lives just to cope with the enormity of information available to them" (p. 6). Reading might also contribute to the improvement of autonomy, as it was found in a study carried out at five public institutions in Colombia (Mendieta et al., 2015). Besides, Krashen (2004) also explains how reading freely promotes autonomy, "when second language acquirers read for pleasure, they can continue to improve in their second language without classes, without teachers, without study, and even without people to converse with" (p. 147). This means that a free voluntary reading program suggests that learners will not only improve in the instructional sessions, but also will continue improving without the teachers' guidance.

\section{Methodology}

Action research was chosen to achieve the objectives of this study. In action research the researcher can assume a double role: as the teacher leading the lessons and the person applying the study. Action research is particularly 
useful and meaningful in the educational context, as it provides educators with the opportunity to identify and deal with specific situations in the classroom through direct observation, as it is conducted on-site through methods common to qualitative research (McKernan \& McKernan, 2013). However, using a mixed methods approach allows the generation and testing of theory, the answering of complex research questions as well as the corroboration of findings (DeCuir-Gunby, 2008). That is why, the researchers decided to collect data in two different types: qualitative and quantitative.

The data was collected from different sources and in different moments as explained in the following sections.

\subsection{Data Collection Instruments}

Instruments were applied as follows:

\subsubsection{Pretest and Posttest}

Two of the instruments used before and after the pedagogical implementation were a pretest and a posttest. Both tests consisted of a 1200-word text, chosen according to the students' CEFR level. The students were allotted 20 minutes to read the text and then, they were given 20 more minutes to write a review about it. Results of studies are more reliable if the same test version is used in the pretest and in the posttest (Liu \& Zhang, 2018). Consequently, considering validity purposes, the teachers applied the same test at the beginning and at the end of the intervention, participants had to follow an established protocol for this purpose: all students had to complete the task in the given time, they were requested to work individually and they could not use any external help. The posttest was applied 11 weeks after the beginning of the implementation. These instruments were used to assess students' active vocabulary use at the beginning and at the end of the study.

\subsubsection{Students' Diaries}

Students' diaries are an effective tool to gather rich participant-focused data that provides clear insights into the perception of usefulness that students have about the implementation. According to Somekh and Lewin (2005), diaries provide information directly from the writer's perspective. In fact, students' diaries allow the researchers to "determine the antecedents, correlates, and consequences of daily experiences" (Bolger, Davis, \& Rafaeli, 2003, p. 586). The information gathered from the diaries used in this study was central for collecting qualitative data about the learners' practical application of the strategies, the issues they faced, the procedures they used to solve them and the processes that the learners carried out before, during and after reading. Therefore, the researchers were able to pinpoint interesting characteristics and trends about students' self-confidence, motivation to use the strategies, strategy implementation and reading progress.

Students were provided with a sample template diary to be completed during their independent reading sessions, they were suggested to keep record of the actions and mental processes that took place during their autonomous reading time. Students gave information about the strategies they used before, during and after the FVR session; issues related to vocabulary they faced and solutions given. If any word was guessed by context, students shared the context clue that helped them to understand, and a list of new vocabulary learned (Appendix B).

\subsubsection{Pre and Post Implementation Surveys}

In order to learn about the students' reading habits, self-direction and motivation levels, the researchers designed and administered pre and post surveys. The first part of the surveys included questions that inquired whether the students read voluntarily, how often they read and which factors they found to be more challenging when reading in English. The second part of the surveys contained questions about the students' levels of self-direction and motivation; whether they could understand a text without the help of a teacher and how interested they felt about reading in English after the implementation. Finally, the surveys asked about the aspects that the students thought would help them improve their reading skills. The pre implementation survey was also used as a needs analysis, which was the starting point of this study (Appendix A).

\subsubsection{Book Reviews}

Participants were asked to read at least three books during the implementation, although some read up to seven books. Students wrote three reviews, about three graded readers, in three different moments. The researchers used these book reviews to measure students' active vocabulary use. Researchers gave students a model of a review at the beginning of the implementation for them to see the parts of a review; but during the assessment, the emphasis given was vocabulary use. Since the project did not focused on rhetorical structure, neither researchers nor students focused on reviews form.

A summary of the data collection instruments is given in the table below (Table 1). 
Table 1. Data collection instruments and implementation stages

\begin{tabular}{ll}
\hline Instrument & Purpose \\
\hline $\begin{array}{l}\text { Diagnostic } \\
\text { survey }\end{array}$ & -Identify the learners' attitudes, needs, strengths and weaknesses. \\
$\begin{array}{l}\text { First review } \\
\begin{array}{l}\text { Students' } \\
\text { diaries }\end{array}\end{array}$ & $\begin{array}{l}\text {-Assess students' active vocabulary use before the implementation. } \\
\text {-Record students' behaviors. }\end{array}$ \\
-Gather information about the implementation of the strategies, reading process and general \\
Book reviews \\
$\begin{array}{l}\text { Post survey } \\
\text { Final review }\end{array}$ & $\begin{array}{l}\text {-Measure students' reading progress and active vocabulary use along the implementation. } \\
\text {-Re-assess the learners' attitudes, needs, strengths and weaknesses after the implementation. }\end{array}$ \\
\hline
\end{tabular}

\subsection{Pedagogical Intervention}

When designing the Free Voluntary Reading intervention, the researchers took into account the information revealed in the needs analysis, such as the necessity of having access to varied texts. This needs analysis arose from the pre implementation survey, and was later compared with the results after the implementation, more details are given in a section below. Then, the researches designed a web page (http://mariorendon86.wixsite.com/thereadingproject) in which they provided learners with a list of 100 graded readers, besides, they shared there the PowerPoint presentations used in class, and some activities for a further practice of the strategies. Participants were asked to pick a graded reader from the provided list every two weeks. The lessons designed guided learners through the discovery of the two target strategies: Guessing Approach and Dictionary Use. The researchers designed nine lesson plans that lasted 1 hour each. At the end of each lesson, an e-learning game (quizzes or kahoot) tested the students' understanding of the new strategies and assessed the lesson objective. These games helped the researchers to identify probable adjustments in the implementation and to provide students with feedback. When students did not get good results in the games, it meant that the objective was not reached, so a new lesson had to be taught in order to make the strategies clearer. In this way, the continuous improvement cycle of action research was carried out.

The implementation took place during the first academic semester in 2016 as shown in the timeline below (Figure 1). According to Liu and Zhang (2018), one semester (3-4 months) is the most appropriate length for extensive reading practices.

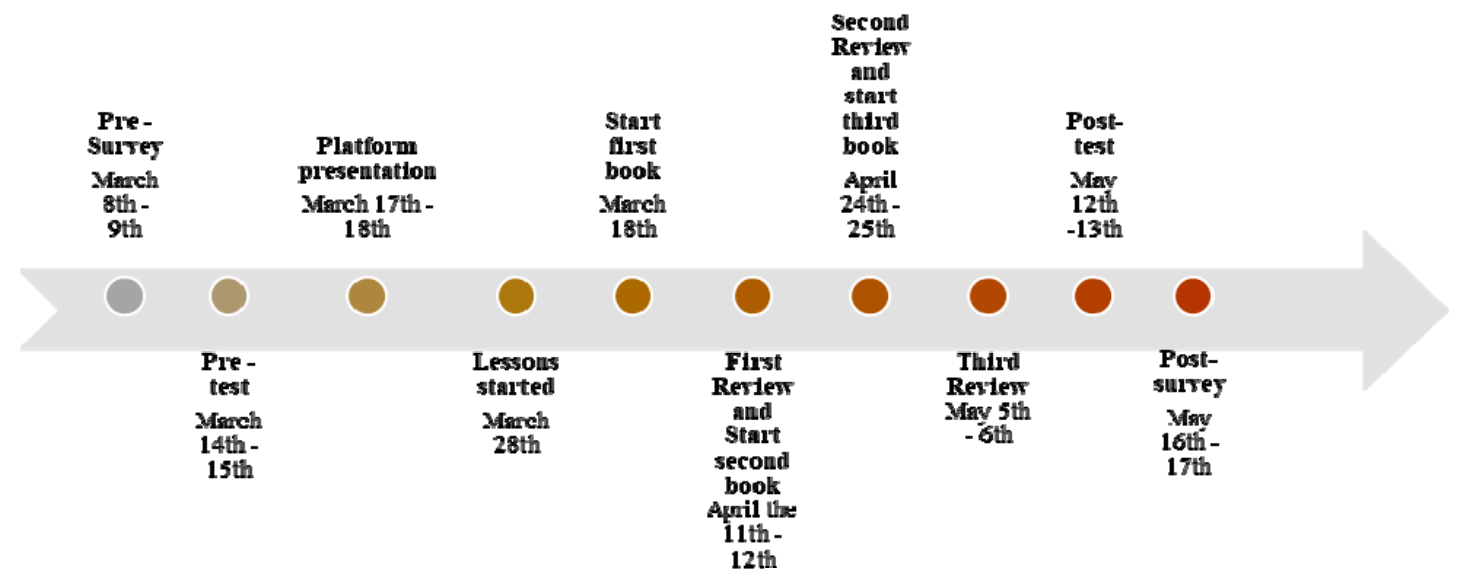

\section{Data Analysis}

Figure 1. Research study timeline

\subsection{Use of Active Vocabulary}

In order to determine the effects of the intervention on students' active vocabulary use, the researchers examined the descriptive statistics of the pre and posttests results, which allowed the analysis of the total number of words written by the students in each test. This helped the researchers measure any substantial numerical differences between the students' results before and after the intervention. Furthermore, the tests required students to write reviews by using complete meaningful sentences. However, since the study did not focus on grammar, all the words written by the students were taken into account regardless of grammatical accuracy. Additionally, it must 
be pointed out that the word count in the posttest excluded any word(s) also used in the pretest, since the purpose was to measure the words learned during the implementation (between the pre and posttest). The words had not been studied in class, only in students' reading sessions.

Moreover, in order to identify a more precise calculation of the students' lexical retention after the implementation, the researchers conducted a data reduction process in which only the total number of verbs, adjectives and nouns (VAN count hereafter) written by the students were taken into account. Additionally, the data obtained from the VAN count allowed the researchers to conduct a more accurate analysis of the percentage gain to better assess to what extent the students' active vocabulary use had improved as a result of the intervention, since only specific parts of speech were considered, and repeated words were excluded.

\subsubsection{Active Vocabulary Use Before and After the Implementation}

It is readily apparent that the results in the posttest were significantly higher than in the pretest as evidenced in Table 2 below. The mean, being a measurement that calculates the averages of the students' scores, shows that they wrote over twice as many words after the implementation. The standard deviation, as an indicator of dispersion, indicates that there was a wider range among the scores. These results suggest that, even though there was growth in active vocabulary use, the gap between those students with better vocabulary retention scores and those with lower vocabulary retention scores increased.

Table 2. Descriptive statistics total word count combined contexts

\begin{tabular}{lll}
\hline & Pretest & Posttest \\
\hline Mean & 29,96 & 71,92 \\
Standard. Deviation & 30,90 & 47,81 \\
Story Word Count & 1024 & \\
& & $7,02 \%$ \\
Percentage & $2,92 \%$ & \\
Percentage gain & $4,10 \%$ & \\
\hline
\end{tabular}

To provide a more elaborate analysis of the students' lexical retention, Table 3 below presents the descriptive statistics regarding the VAN count. For this analysis, it was necessary to sort out the words in each students' reviews, omitting repeated words and parts of speech other than verbs, adjectives and nouns. The same process was then carried out with the story used in the pre and posttest which contained a total of 1024 words. In order to obtain the VAN count of the story students read, the researchers used an online website called Text Inspector (https://textinspector.com), which provided the Token (588) and Type (310) counts, which helped the researchers to determine that all the verbs, adjectives and nouns, repeated words excluded, constituted 30,27 percent of all the words in the story.

Table 3. Descriptive statistics VAN count combined contexts

\begin{tabular}{lll}
\hline & Pretest & Posttest \\
\hline Media & 13,4 & 17,12 \\
Deviation standard & 9,28 & 7,54 \\
Story VAN & 310 & \\
VAN percentage & $4,32 \%$ & $5,52 \%$ \\
Percentage gain & $1,20 \%$ & \\
\hline
\end{tabular}

The results obtained from the VAN analysis establish that there was indeed an increase in the number of VAN that students were able to write in their after the implementation.

\subsubsection{Delayed Use of Vocabulary}

In order to measure the effect of the study on the students' delayed use of vocabulary, the researchers measured the number of words that the students had written as new vocabulary in their diaries versus the ones used in the book reviews. Since the sessions to write the reviews took place without previous notice, those words used both in the diaries and in the reviews were considered as acquired by the learners. During the writing time, students were not allowed to use their diaries nor any other external help. 
Students were asked to read at least three books, since the implementation followed the stages of an action research project: reflect, plan, act, observe, reflect, and repeat the cycle (Handscomb \& MacBeath, 2006), so three opportunities to write a review were given. Of note is that some of the students read a larger number of books.

Table 4 below shows the average number of acquired words per book, according to the new words used in their reviews.

Table 4. Acquired word count

\begin{tabular}{lllllll}
\hline & Book 1 & Book 2 & Book 3 & Totals & Mean & St deviation \\
\hline Context 1 & 2 & 6 & 5 & 13 & 0,92 & 1,63 \\
Context 2 & 4 & 7 & 7 & 18 & 1,64 & 1,75 \\
Combined & 6 & 13 & 12 & 32 & 1,24 & 1,69 \\
\hline
\end{tabular}

At first glance, it is noticeable that the number of words acquired by the students rose in the second review; nevertheless, it did not show any additional improvement in the last assessment. In addition, the tables indicate that, although Context 2 obtained higher scores, the difference between contexts was not considerable.

\subsection{Self-Directedness and Vocabulary Acquisition}

\subsubsection{Analysis of Self-Directed Behaviors}

Regarding the second objective of the study, which is the correlation between self-directedness and vocabulary acquisition, the researchers focused first on finding evidence of students' autonomy through the analysis of the individual themes (strategy use, dictionary use and independence from the teacher) by consulting the students' diaries and the post-implementation survey.

First, the students' diaries were examined in order to find evidence of vocabulary learning strategies, with the purpose of determining which students had actually applied the strategies taught in class and which had not. The students' diaries were analyzed and transformed into numbers such that if a learner explicitly mentioned the use of specific strategies, then a score of " 1 " was assigned to the student; otherwise, when a student failed to mention the use of strategies or referred to the use of translators, a score of " 0 " was assigned.

The same process was then carried out with the students' answers in the post-implementation survey. The two questions taken into account were yes/no questions related to dictionary use and dependence on their teacher. In this case, when a learner's answer indicated independence from the dictionary or their teacher, then a score of " 1 " was assigned to the student; otherwise, a score of " 0 " was assigned. This transformation of the data and its dichotomization led to the formation of an inter-respondent matrix of themes (Onwuegbuzie \& Johnson, 2003) that consisted only of $0 \mathrm{~s}$ and $1 \mathrm{~s}$. This matrix allowed the researchers to calculate the percentages of each theme, as shown in Table 5 below.

Table 5. Self-directedness themes frequency rate combined contexts

\begin{tabular}{llll}
\hline \multicolumn{2}{l}{ DEPENDENCE ON TEACHER } & & \\
\hline \multirow{2}{*}{ Do not depend } & Frequency & Percent & Cumulative percent \\
Depend & 17 & $68,00 \%$ & $68 \%$ \\
Total & 8 & $32,00 \%$ & 100 \\
\hline DEPENDENCE ON TRANSLATOR & $100,00 \%$ & \\
\hline & 25 & Percent & Cumulative percent \\
Do not depend & Frequency & $88,00 \%$ & $88 \%$ \\
Depend & 22 & $12,00 \%$ & 100,00 \\
Total & 3 & $100,00 \%$ & \\
\hline STRATEGY USE & 25 & & Cumulative percent \\
\hline
\end{tabular}




\begin{tabular}{llll}
\hline No use & 9 & $36,00 \%$ & 100 \\
Total & 25 & $100,00 \%$ & \\
\hline
\end{tabular}

According to these percentages, a considerable number of students ( 8 students, $32 \%$ ) still saw the teacher as necessary to understand a text in English after the implementation. Although $0 \%$ of students answer "no" to the question: "Do the strategies learnt in class help you understand a text in English without a teacher's help?" 9 students answered "sometimes", which was taken as a degree of dependence on the teacher.

On the other hand, the number of students who expressed dependence on the translator was rather low, only 3 students. Interestingly, the number of students who did not show a clear record of strategy use in their diaries was virtually the same as those who admitted relying on their teachers for text understanding. The percentages regarding translator use were substantially low, and the students who indicated strategy use was over $60 \%$.

\subsubsection{Correlation Between Self-Directedness and Vocabulary Acquisition}

Subsequently, active vocabulary use scores from both contexts computed in a previous stage were added to the matrix in order to conduct a canonical correlation analysis (Thompson, 1984). This analysis examined the multivariate relationship between the three self-direction themes and the two active vocabulary use scores. This procedure was conducted using a special statistical MS Excel TM extension called XLSTAT. For this particular kind of analysis, coefficients with the effect sizes larger than .3 were considered as strong correlation indicators, as suggested by Lambert and Durand (1975); the alpha level was set at 0.05 .

Therefore, the results, as shown in Table 6, suggest that there is a strong correlation between the use of incidental and intentional vocabulary strategies and active vocabulary use. In other words, those students who applied vocabulary-learning strategies during the implementation obtained better results in the vocabulary tests, particularly the delayed vocabulary use test. This puts forth the claim that the students who applied vocabulary-learning strategies during the reading process were more able to use new vocabulary actively sometime after reading the books. Likewise, there is a remarkable correlation between the use of strategies and independence from the teacher.

Table 6. Canonical correlation analysis combined contexts

\begin{tabular}{|c|c|c|c|c|c|}
\hline VARIABLES & Pre vs post & Journal vs review & Independence teacher & Independence translator & Use of strategy \\
\hline Pre vs post & 1 & 0,161 & 0,266 & 0,256 & 0,328 \\
\hline Journal vs. diary & 0,161 & 1 & 0,099 & 0,054 & 0,411 \\
\hline Independence teacher & 0,266 & 0,099 & 1 & 0,274 & $\mathbf{0 , 5 5 7}$ \\
\hline Independence translator & 0,256 & 0,054 & 0,274 & 1 & 0,236 \\
\hline Use of strategy & 0,328 & 0,411 & $\mathbf{0 , 5 5 7}$ & 0,236 & 1 \\
\hline
\end{tabular}

Such correlation suggests that those students who applied the strategies taught during the study became more autonomous. Data contained in the students' diaries confirm the aforementioned suggestion:

"I adapted the words to the context of the reading, and I'm now getting a better understanding of the text without a using a translator or asking the teacher" (Excerpt No. 1 S7. Students' diaries).

"To know the definition of certain words without having to use the dictionary or ask the teacher, I review the entire context of the reading, trying to guess what it means" (Excerpt No. 2 S5. Students' diaries).

\subsection{Free Voluntary Reading Habits}

In order to meet the third objective of the study, the last stage involved the comparison of the students' answers in the post-implementation survey with their answers in the diagnostic survey, regarding whether the implementation would produce a positive change on the students' voluntary reading habits. The researchers focused specifically on the questions concerning students' volition, reading frequency and perceived difficulty to read in English.

Figures 2 and 3 evidence that the students presented an improvement in their disposition towards reading texts in English, as well as the frequency at which they do it. 


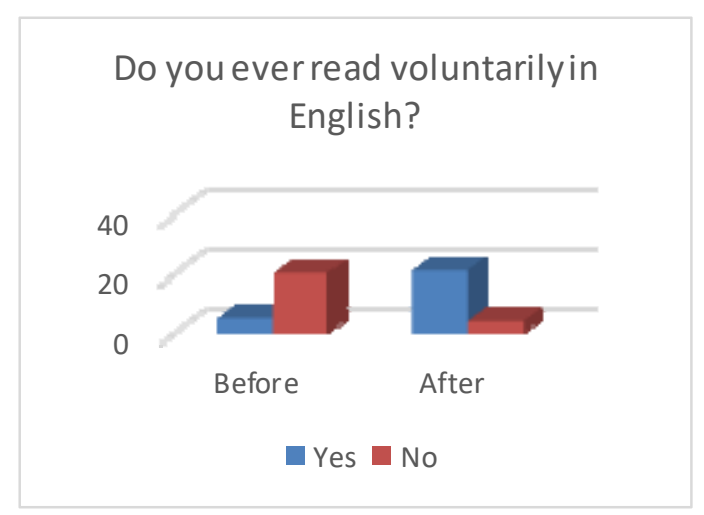

Figure 2. Voluntary reading before and after implementation
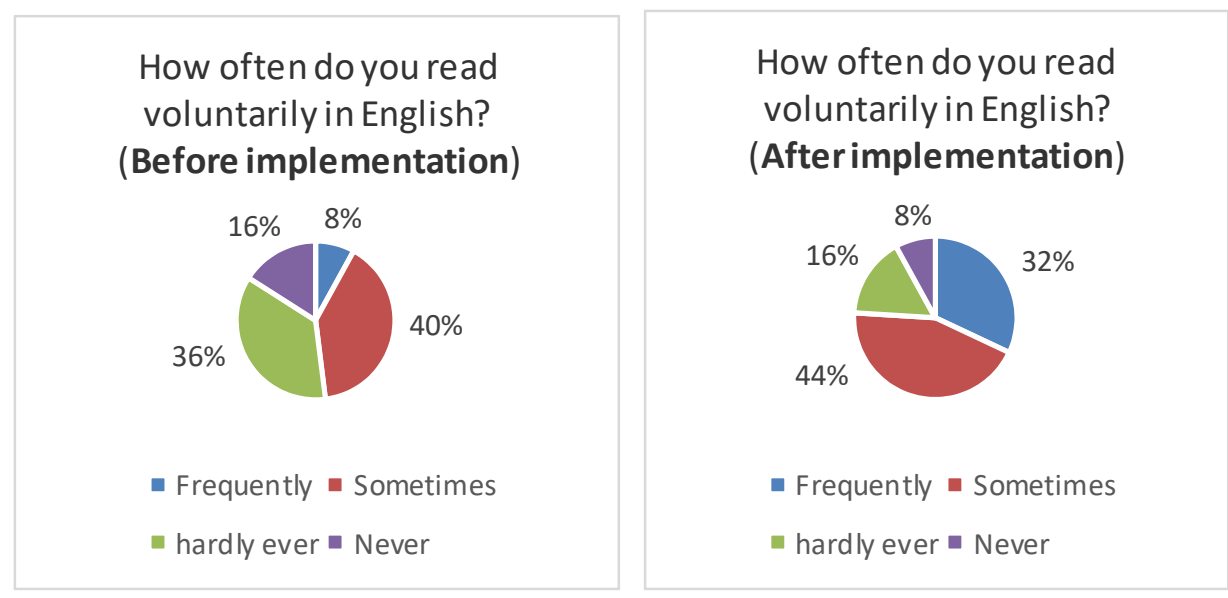

Figure 3. Voluntary reading frequency before and after the implementation

Figure 2 shows a crucially important improvement in the students' attitude towards reading voluntarily in English; the number of students who answered positively after the intervention increased by $62 \%$. Likewise, figure 3 shows that there was a notable rise in the number of students who read frequently, which grew fourfold, the number of students who read frequently rose by $24 \%$.

In terms of perceived difficulty, it was revealed that the intervention had a positive effect on most of the students. The number of the learners who thought that reading in English was difficult decreased, which represented an increase in the number of the students who considered the activity as normal. See Figure 4 below.

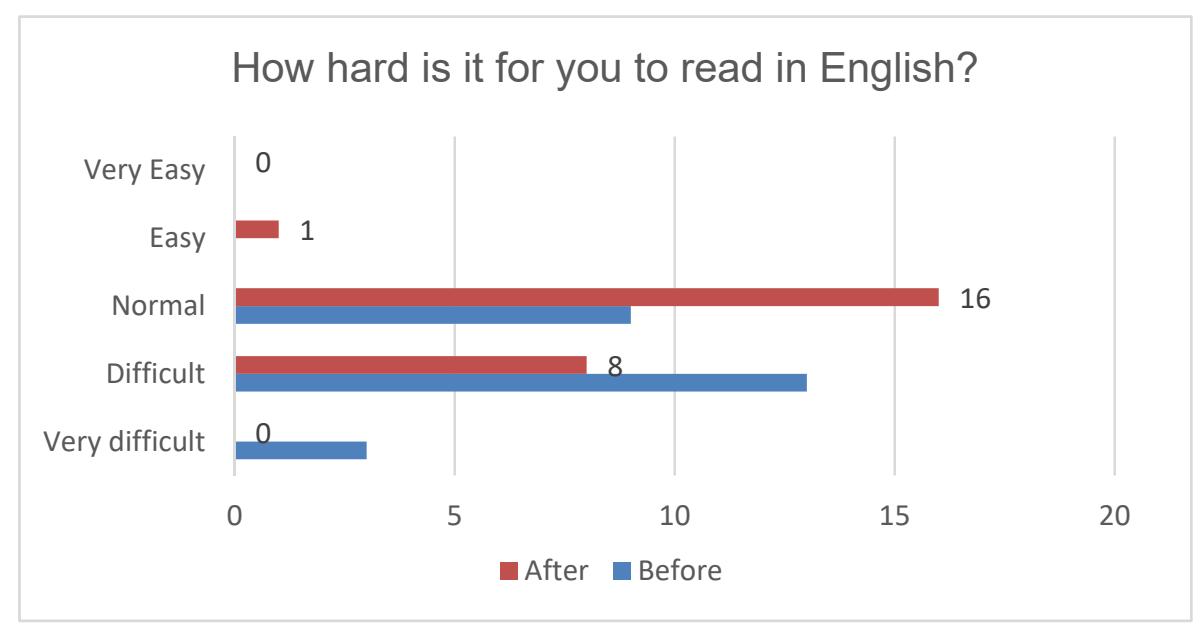

Figure 4. Pre-and post-implementation perceived difficulty to read in English 


\section{Conclusions and Pedagogical Implications}

\subsection{Significance of the Results}

The results of this study revealed that the implementation of a free voluntary reading study supported by vocabulary-learning strategy instruction was successful on improving active vocabulary use and vocabulary retention. Also, the program helped students to feel more confident and positive about their reading abilities, which in turn, brought significant positive changes in the students' attitudes toward reading in English and their reading frequency habits.

With regards to the students' active vocabulary use, the noticeable rise of total words written immediately after reading the same text that was also used in the diagnostic stage, showed that the participants became more confident about their foreign language use. Likewise, a strong correlation among active vocabulary use with the use of vocabulary-learning strategies was found. In the same way, results showed a strong correlation among vocabulary-learning strategies and self-directed behaviors.

Similarly, most of the students affirmed that after the implementation they felt more secure in being independent readers without the teachers' help. In the same way, as one of the strategies taught dealt with dictionary use, the vast majority of the learners declared that their use of language translators decreased. Therefore, the students are now expected to be able to keep track of their learning process and to solve most of the vocabulary issues they find when reading by themselves.

Finally, the study also contributed to the improvement of the students' motivation towards reading, attitude and reading habits, which at the same time support autonomy. On one hand, data demonstrated that the students' attitude towards reading voluntarily in English significantly improved in comparison to the data collected before the implementation. Similarly, a large number of the learners announced that they were much more motivated to read for pleasure after their participation in this experience; and the data, showing a rise in reading habits, confirmed that. Likewise, the frequency of their autonomous reading sessions increased considerably by the end of the study due to the implementation, so an improvement in their perceptions regarding the difficulty of the skill was found.

As a conclusion, this research agrees with previous studies that have confirmed the positive impact of reading on vocabulary growth. Besides, it adds the component of metacognitive vocabulary-learning strategies to improve students' habits, perceptions and autonomy when reading voluntarily. Similarly, the study adds an analysis with encouraging results regarding correlations among active vocabulary use with the use of vocabulary-learning strategies, as among vocabulary-learning strategies and self-directed behaviors.

\subsection{Limitations of the Present Study}

The post-implementation survey had to be conducted too soon after completing the intervention, which may have made difficult to follow up students' reading habits. Finally, the researchers were not able to carry out a deeper analysis of the long-term effects of the intervention on vocabulary acquisition and reading performance, since after the implementation, students continued with their academic process in other groups, with other teachers.

\subsection{Further Research}

Linguists have claimed that FVR develops other components of the speech such as grammar, spelling and writing (Krashen, 2004; Lee, Krashen, \& Gribbons, 1996; Lee, Krashen, \& Tse, 1997; Cho, Park, \& Krashen, 2008). Although this paper focuses on vocabulary retention, it would be beneficial to observe the potential benefits of this kind of study in other language skills. Moreover, the learners demonstrated that they also developed an interest in reading in their native language by participating in this FVR program. For this reason, teachers of other areas might find a similar implementation valuable as well.

\section{References}

Bolger, N., Davis, A., \& Rafaeli, E. (2003). Diary methods: Capturing life as it is lived. Annual review of psychology, 54(1), 579-616. https://doi.org/10.1146/annurev.psych.54.101601.145030

Boonmoh, A. (2012). E-dictionary use under the spotlight: Students' use of pocket electronic dictionaries for writing. Lexikos, 22, 43-68. https://doi.org/10.5788/22-1-997

Cho, K. S., Park, E. J., \& Krashen, S. (2008). Reading in English by children in Korea: Frequency, effectiveness and barriers. Indonesian Jelt, 4(1), 18-25.

Clarke, D. F., \& Nation, I. P. (1980). Guessing the meanings of words from context: Strategy and techniques. System, 8(3), 211-220. https://doi.org/10.1016/0346-251X(80)90003-2 
DeCuir-Gunby, J. (2008). Designing mixed methods research in the social sciences: A racial identity scale development example. In J. Osborne (Ed.), Best Practices in Quantitative Methods. (pp. 125-136). Thousand Oaks, CA: Sage. https://doi.org/10.4135/9781412995627.d11

Durán, D., \& Rendón, M. (2016). Incidental and intentional vocabulary learning strategy instruction to promote vocabulary retention and self-directedness. A thesis in English Language Teaching for Self-Directed Learning (master's thesis).Universidad de La Sabana. Chía, Colombia.

Edwards, L. (2009). How to teach vocabulary. Pearson Education. Retrieved from http://pearsonlongman.com.html

Griffiths, C. (2008). Lessons from good language learners. Cambridge University Press. https://doi.org/10.1017/CBO9780511497667

Handscomb, G., \& MacBeath, J. (2006). Professional development through teacher enquiry. Set: Research information for teachers, 1, 40-46.

Hiemstra, R. (1994). The sourcebook for self-directed learning. Massachusetts: HRD Press.

Hu, M., \& Nation, I. S. P. (2000). Unknown vocabulary density and reading comprehension. Reading in a Foreign Language, 13, 403-430.

Krashen, S. D. (2004). The power of reading: insights from the research: insights from the research. ABC-CLIO.

Krashen, S. D., \& Terrell, T. D. (2000). The natural approach: Language acquisition in the classroom. (2nd ed.) England: Pearson Education.

Lambert, Z. V., \& Durand, R. M. (1975). Some precautions in using canonical analysis. Journal of Marketing Research, 12(4), 468-475. https://doi.org/10.2307/3151100

Laufer, B. (2001). Reading, word-focused activities and incidental vocabulary acquisition in a second language. Prospects, 16(3), 44-54.

Laufer, B., \& Yano, Y. (2001). Understanding unfamiliar words in a text: Do L2 learners understand? How much they don't understand? Reading in a Foreign Language, 13, 549-566.

Lee, S. Y., Krashen, S., \& Tse, L. (1997). The author recognition test and vocabulary knowledge: a replication. Perceptual and motor skills, 85, 1428-1430. https://doi.org/10.2466/pms.1997.85.3f.1428

Lee, Y. O., Krashen, S. D., \& Gribbons, B. (1996). The effect of reading on the acquisition of English relative clauses. Institut voor Togepaste Linguistik, 263-273. https://doi.org/10.1075/itl.113-114.04lee

Liu, J., \& Zhang, J. (2018). The effects of extensive reading on English vocabulary learning: a meta-analysis. English language teaching, 11(6), 1-15. https://doi.org/10.5539/elt.v11n6p1

McKernan, J., \& McKernan, J. (2013). Curriculum action research: A handbook of methods and resources for the reflective practitioner. Abingdon: Routledge.

McQuillan, J. (1998). The literacy crisis: False claims, real solutions. California: Heinemann.

Mendieta, J., Múnera, L., Olmos, T., Onatra, C., Pérez, P., \& Rojas, E. (2015). Fostering reading comprehension and self-directed learning in a collaborative strategic reading (csr) setting. Íkala, Revista de Lenguaje y Cultura, 20(1), 15-42. https://doi.org/10.17533/udea.ikala.v20n1a02

Nation, I. S. (2001). Learning vocabulary in another language. Cambridge, England: Cambridge University Press. https://doi.org/10.1017/CBO9781139524759

Onwuegbuzie, A. J., \& Johnson, R. B. (2004). Mixed methods research: A research paradigm whose time has come. Educational researcher, 33(7), 14-26. https://doi.org/10.3102/0013189X033007014

Somekh, B., \& Lewin, C. (2005). Research methods in the social sciences. London: SAGE.

The British Council, (2008). Retrieved from https://www.teachingenglish.org.uk/article/passive-vocabulary

Thompson, B. (1984). Canonical Correlation Analysis: Uses and Interpretation, California: SAGE. https://doi.org/10.4135/9781412983570

Thornbury, S. (2002). How to teach vocabulary. Malaysia: Pearson Educated Limited.

WebLingua. (n.d.). Text Inspector. Retrieved from https://textinspector.com/ 


\section{Appendix A. Pre and Post implementation surveys}

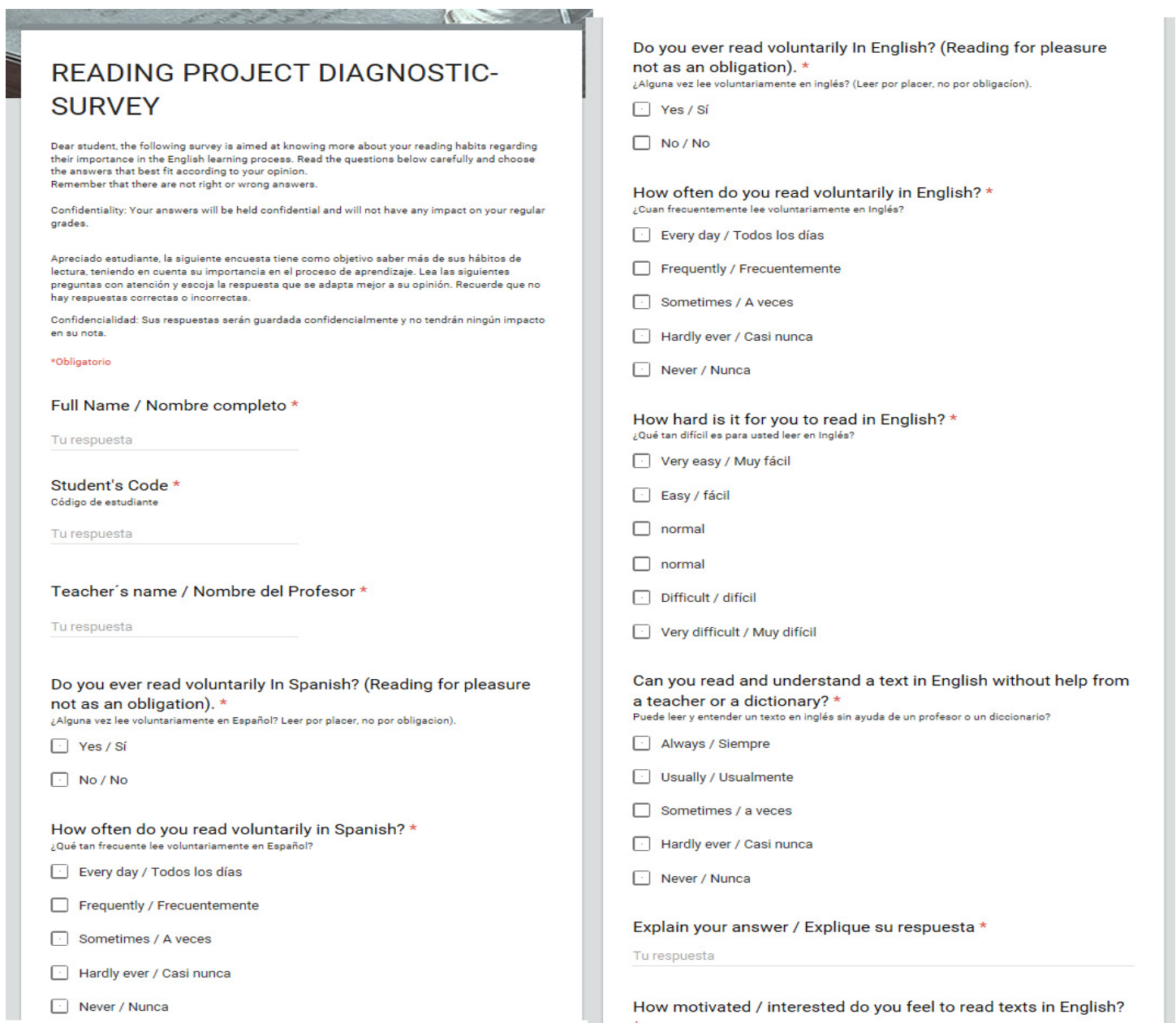


¿Cuan motivado / interesado se siente a leer textos en Inglés?

$\square$ Extremely / Extremadamente

$\square$ Very / Muy

Moderately / Moderadamente

$\square$ slightly / Ligeramente

$\square$ Not at all / para nada

Why / Por que?*

Tu respuesta

Which of the following aspects do you think would motivate you to read more in English? (You can choose more than one option). *

Cuál de los sig
una opción).

Frequent reading / Lectura Frecuente

$\square$ A good range of vocabulary / Un vocabulario mas extenso

$\square$ Grammatical competence / Competencia gramatical

Reading comprehension strategies / Estrategias de comprension de lectura

$\square$ Availability and variety of books / Disponibilidad y variedad de libros

$\square$ otro

Which of the following aspects do you think would help you to improve your reading skills? (You can choose more than one option) *

¿Cuál de los siguientes aspectos piensa que le ayudaria a mejorar su habilidad lectora) (Pued

$\square$ Grammatical competence/ Competencia gramatical

$\square$ Read more frequently / Leer mas frequentemente

Reading compehension strategies / estrategias de comprension de lectura

$\square$ A good range of vocabulary / Un vocabulario mas extenso

$\square$ Learning aid tools / Herramientas de ayuda para el aprendizaje

$\square$ otro

Do you use technology to learn English? *

¿Utiliza la tecnologia para aprender Inglée?

$\mathrm{O}$ Yes/Si
No/ No

If "yes", explain which tools or resources you use.

En caso de que 'si', explique cuales herramientas o recursos usa.

Tu respuesta

Would you like to have a website where you could find a wide variety of books and learning aids? *

Le gustaria tener una pagina donde pudiera encontrar una gran variedad de libros y ayudas do

Y Yes / Sí

O No/No

Do you know what a book review is? / ¿Usted sabe qué es una reseña de un libro?

Explain briefly what you think a book review is/ Explique brevemente que es para usted una reseña de un libro.

Tu respuesta

How well do you think you could write a book review? *

¿Qué tan bien cree usted que podria escribir una reseña?

Very well / Muy bien

$\mathrm{O}$ well / bien

O Fairly well / Aceptable

Not very well / No muy bien

I do not know how to do it / No se hacerlo

Which of the following aspects do you think can help you to improve your writing skills? (You can choose more than one option) *

cual de los siguientes aspectos piensa que puede ayudarle para mejorar sus habilidades de

$\square$ Practice / Práctica

Wider vocabulary/ Vocabulario mas extenso

$\square$ Grammatical competence / Competencia gramatical

$\square$ Read more / Leer mas

$\square$ otro: 


\section{Appendix B. Students' diaries samples}
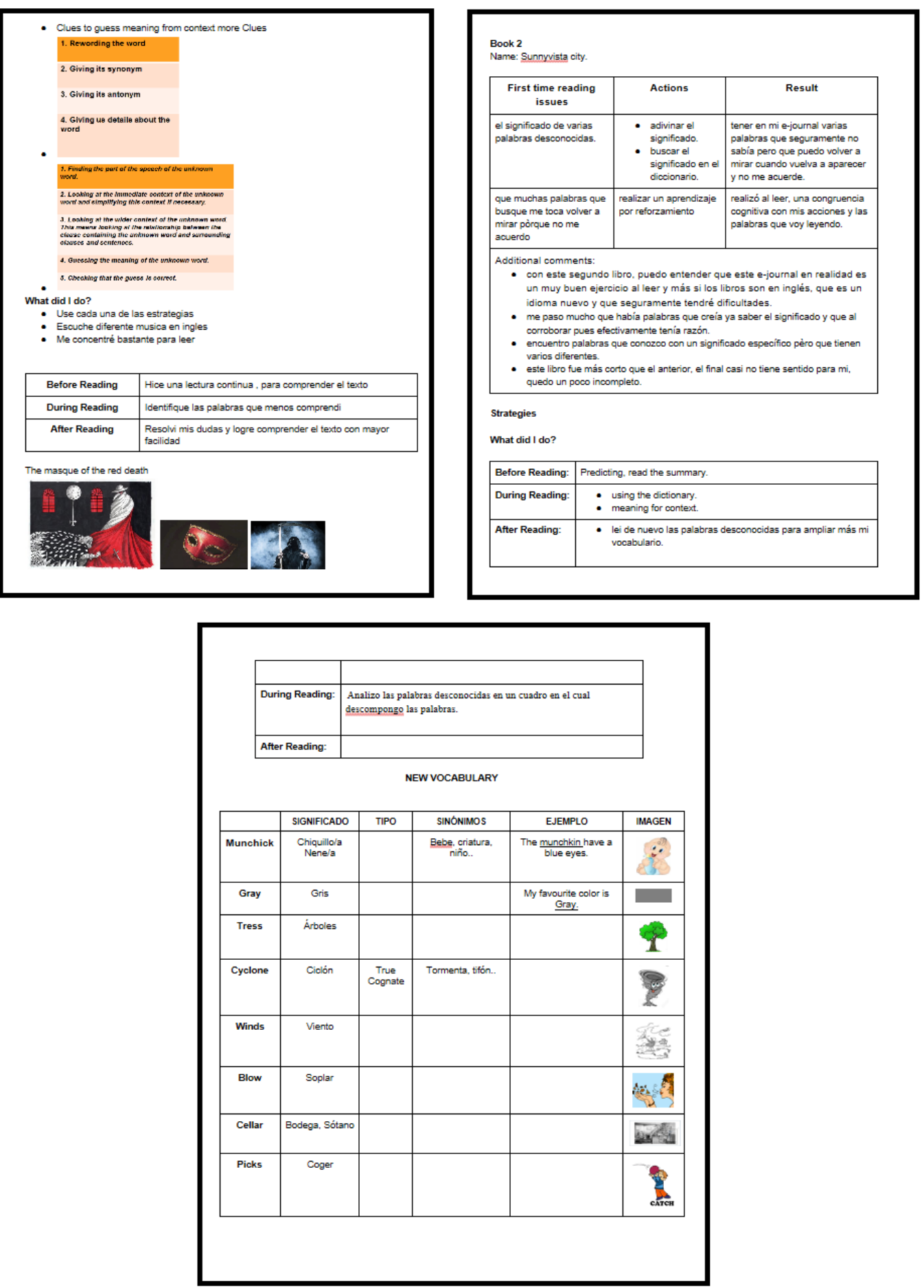

\section{Copyrights}

Copyright for this article is retained by the author(s), with first publication rights granted to the journal.

This is an open-access article distributed under the terms and conditions of the Creative Commons Attribution license (http://creativecommons.org/licenses/by/4.0/). 